\section{OP0057 THE PATIENTS' KNOWLEDGE ABOUT THEIR DISEASE: A FRENCH MULTICENTRIC SURVEY IN ANKYLOSING SPONDYLITIS (AS)}

P Claudepierre, RM Flipo, J Sibilia, JM Berthelot, P Goupille, S Cortinovis, X Chevalier, D Wendling. Rheumatology, Henri Mondor Hospital, Créteil, France

\subsection{6/annrheumdis-2001.349}

Background It is known that, in chronic diseases, patient education is a factor of good compliance and good disease management. An index was recently proposed to assess the level of knowledge in AS. ${ }^{1}$

Objectives To assess the level of knowledge of a population of AS patients from different tertiary care centres in France, and to identify some factors linked with this level.

Methods Study:multicentric cross-sectional study. No structured educational program was used in these centres at the time of the study. Patients: Inclusion criteria were New York criteria of AS and patients had to read French fluently. Data collected: demographic and sociocultural, disease characteristics, the index of knowledge in a French version (obtained from a double translation) giving a maximum score of 25 . Statistical analysis: to seak a link between the knowledge score and collected factors, usual non parametric tests were used.

Results The mean score of the 95 included patients was only 16.4 (S. D. 4.8). The percentages of correct answers were not equally distributed among the 4 groups or domains of questions. The duration of disease management in a tertiary care centre appeared to be positively linked to the level of knowledge $(r=$ 0.28 with $\mathrm{p}=0.01$, for the global score on 25 points, and $\mathrm{r}=$ 0.26 with $\mathrm{p}=0.02$, for the number of good answers (on 14) per patient). It was also observed that the level of knowledge was better in females than males, and in patients who have previously read on the disease or who knew the association of AS patients. No interaction was found between the factor "sex" or the factor "duration of disease management in a tertiary care centre" and the other identified factors, suggesting that they are independent factors associated with the level of knowledge. Conversely, the 3 other factors, e.g., level of education in 2 classes, previous reading, knowing of the association, were statistically linked two by two. The other tested factors were not significantly linked with the level of knowledge: age of the patients, duration of the disease, characteristics of the disease (axial or peripheral, psoriasis, radiological severity).

Conclusion The level of knowledge of these patients appears lower than this observed in the previous UK study, reinforcing the positive role of educational programs. These data will help to determine in which domains and in which patients the highest effort of education should be initially done.

\section{REFERENCE}

1 Lubrano E, et al. Br J Rheumatol. 1998;37:437-41

\section{OP0058 EFFICACY OF INFLIXIMAB IN SEVERE REFRACTORY ANKYLOSING SPONDYLITIS (AS). RESULTS OF AN OPEN- LABEL STUDY}

${ }^{1} \mathrm{MA}$ Breban, ${ }^{2} \mathrm{E}$ Vignon, ${ }^{3} \mathrm{P}$ Claudepierre, ${ }^{4} \mathrm{~A}$ Saraux, ${ }^{5} \mathrm{D}$ Wendling, ${ }^{6} \mathrm{E}$ Lespesailles, ${ }^{7} \mathrm{~L}$ EullerZiegler, ${ }^{8} \mathrm{~J}$ Sibilia, ${ }^{9} \mathrm{~A}$ Perdriger, ${ }^{10} \mathrm{C}$ Alexandre, ${ }^{1} \mathrm{M}$ Dougados. ${ }^{1}$ Rheumatology Division, Cochin Hospital, Paris; ${ }^{2}$ Rheumatology Division, Lyon; ${ }^{3}$ Rheumatology Division, Créteil; ${ }^{4}$ Rheumatology Division, Brest; ${ }^{5}$ Rheumatology Division, Besançon; ${ }^{6}$ Rheumatology Division, Orléans; ${ }^{7}$ Rheumatology Division, Nice; ${ }^{8}$ Rheumatology Division, Strasbourg; ${ }^{9}$ Rheumatology Division, Rennes; ${ }^{10}$ Rheumatology Division, Saint-Etienne, France

\subsection{6/annrheumdis-2001.350}

Background Early reports have emphasised the efficacy of the anti-TNF-alpha monoclonal antibody, infliximab, to treat spondylarthropathy patients. Further studies are required to evaluate the extent of such efficacy in large subgroups of well-defined patients.

Objectives To examine the effect of infliximab, in severe AS with predominant axial symptoms.

Methods Patients suffering of severe AS, with evidence of systemic inflammation (modified New-York criteria; BASDAI $>=$ 30/100; CRP $>=15 \mathrm{mg} / \mathrm{l})$ ), and without present peripheral arthritis or extraskelettal manifestation were included. Previous DMARD's had to be discontinued for $>=3$ months. Intake of NSAID had to be stable. Eligible patients received 3 infusions of infliximab $(5 \mathrm{mg} / \mathrm{kg}$, weeks 0,2 and 6). Clinical and biological monitoring was planned for 6 months.

Results We enrolled 48 parents $(36 \mathrm{M} / 12 \mathrm{~F}$; mean age $=36 \pm 9$ yr); 41/46 (89\%) were HLA-B27+; 43 (90\%) completed the treatment, as scheduled, whereas 5 received only 2 infusions. Interim result (wk 8) is shown, and compared to baseline in the table. Altogether, 44 patients (92\%) were responders, as defined by a reduction of global pain on VAS of at least $20 \%$, as compared to baseline level.

\begin{tabular}{lllll}
\multicolumn{5}{l}{ Abstract OP0058 Table 1 } \\
\hline & Baseline & Week 8 & Variation (\%) & P value \\
\hline Disease activity (VAS) & $70 \pm 21$ & $18 \pm 21$ & $-74 \%$ & $<0.0001$ \\
Globlal pain (VAS) & $67 \pm 22$ & $16 \pm 2$ & $-75 \%$ & $<0.0001$ \\
BASDAI & $57 \pm 16$ & $16 \pm 14$ & $-73 \%$ & $<0.0001$ \\
BASFI & $61 \pm 21$ & $19 \pm 2$ & $-70 \%$ & $<0.0001$ \\
CRP (mg/L) & $50 \pm 31$ & $8 \pm 11$ & $-85 \%$ & $<0.0001$ \\
\hline
\end{tabular}

Conclusion Our data confirm the remarkable efficacy of infliximab in AS. It indicate that most, patients suffering of inflammatory active AS promptly and dramatically respond to this treatment.

\section{OP0059 INFLIXIMAB IN REFRACTORY SPONDYLOARTHROPATHIES; PRELIMINARY RESULTS IN A SPANISH POPULATION}

${ }^{1} \mathrm{E}$ Collantes, ${ }^{1} \mathrm{MC}$ Muñoz-Villanueva, ${ }^{2} \mathrm{R}$ Sanmarti, ${ }^{2} \mathrm{JD}$ Cañete, ${ }^{3} \mathrm{~J}$ Gratacos, ${ }^{4} \mathrm{P}$ Zarco, ${ }^{5} \mathrm{C}$ Gonzalez, ${ }^{6} \mathrm{JC}$ Torre. ${ }^{1}$ Rheumatology, Hospital Universitario Reina Sofia, Cordoba; ${ }^{2}$ Rheumatology, Hospital Clinic, Barcelona; ${ }^{3}$ Rheumatology, Hospital Parc Tauli, Sabadell; ${ }^{4}$ Rheumatology, Fundacion Hospital, Alcorcon; ${ }^{5}$ Rheumatology, Hospital Gregorio Marañon, Madrid; ${ }^{6}$ Rheumatology, Hospital Monte Naranco, Oviedo, Spain

10.1136/annrheumdis-2001.351

Background Infliximab, a chimeric anti-TNF-alpha antibody has been used successfully for the treatment of rheumatoid arthritis 